\section{AL-AZHAR Dental Journal}

F o r

G
The Official Publication of The Faculty of Dental Medicine For Girls, Al-Azhar University Cairo, Egypt.

Print ISSN 2537-0308 • Online ISSN 2537-0316

ADJ-for Girls, Vol. 7, No. 2, April (2020) — PP. 179:187

\title{
Remineralizing Effect of Nanofilled Glass Ionomer Combined with Titanium Dioxide Nanoparticle and Nanohydroxyapatite in Root Caries-like Lesions
}

\author{
Meneg A. Muhriz ${ }^{1 *}$, Maha A. Niazy² and Doaa A. Elsharkawy ${ }^{3}$
}

\begin{tabular}{|l|} 
Codex : 24/2004 \\
azhardentj@ azhar.edu.eg \\
http://adjg.journals.ekb.eg \\
\hline DOI: 10.21608/adjg.2020.10808.1133 \\
\hline $\begin{array}{l}\text { Restorative Dentistry } \\
\text { (Removable Prosthodontics, Fixed } \\
\text { Prosthodontics, Endodontics, Dental } \\
\text { Biomaterials, Operative Dentistry) }\end{array}$ \\
\hline
\end{tabular}

\section{KEYWORDS}

Nanoparticle,

Nano hydroxyapatite,

Titanium dioxide,

Glass Ionomer

\begin{abstract}
Purpose: This study designed to evaluate the remineralizing effect of nanofilled glass ionomer combined with titanium dioxide nanoparticle and nano hydroxyapatite in root caries like-lesions. Materials and Methods: sixty specimens from sound human premolars, standardized rounded class $\mathrm{V}$ cavities were prepared in the middle of cervical one third of the labial surface of root. Then the specimens were divided into three main groups according to the experimental restored material (20 specimens each). Group (A): received nanofilled glass ionomer (NGI), group (B): received $10 \%$ nano hydroxyapatite (NHA) incorporated into conventional glass ionomer (GI), and group (C): received $10 \%$ titanium dioxide nanoparticles $\left(\mathrm{TiO}_{2} \mathrm{NPs}\right.$ ) incorporated in conventional glass Ionomer (GI). Each group was further subdivided into two subgroups of (10 each), according to the topical application of nano hydroxyapatite solution either the surface was treated with $10 \%$ nano hydroxyapatite solution (I), or the surface was not treated (II). EDAX measurements were done for all specimens before demineralization, after demineralization, and after remineralization. Results: all materials caused significance remineralization of dentin. When comparing the materials effect on remineralization, (NHA) and (NGI) had much higher phosphors and calcium $\%$ change than $\left(\mathrm{TiO}_{2} \mathrm{NPs}\right)$ when used without (NHA) coat. In comparing use of coat of NHA solution, results showed no significant effects in remineralization, except with $\mathrm{TiO}_{2}$ NPs. Conclusion: Modification of conventional GI restorations using nanoparticles is beneficial to dentin remineralization. NHA topical coat has limited beneficial effect when used in conjunction with NHA and NGI restoration. $\mathrm{TiO}_{2} \mathrm{NPs}$ although produces remineralization, is of lesser value than NHA.
\end{abstract}

- Paper extracted from Master thesis titled "Remineralizing Effect of Nanofilled Glass Ionomer Combined with Titanium Dioxide Nanoparticle and Nano Hydroxyapatite in Root Caries like-lesions"

1. Dentist at Ministry of Health, Tripoli, Libya.

2. Professor and Head of Operative Dentistry, Faculty of Dental Medicine for Girls, Al-Azhar University, Cairo, Egypt

3. Lecturer of Operative Dentistry, Faculty of Dental Medicine for Girls, Al-Azhar University, Cairo, Egypt

* Corresponding author email: menegmuhriz@yahoo.com 


\section{INTRODUCTION}

Root caries is a common problem among the elderly. It occurs on the root of the tooth. Root caries most often occurs supragingivally, at or close to the cemento-enamel junction (within $2 \mathrm{~mm}$ ). The location of root caries has been positively associated with age and gingival recession. Root caries occurs in a location adjacent to the crest of the gingiva where dental plaque accumulates ${ }^{(1,2)}$.

The etiology of root caries is multifactorial, the factors implicated in the development of root lesions include dietary habits, microbial plaque, and decreased salivary flow. Root lesions are often very difficult to restore due to their location, problems with moisture control ${ }^{(3,4)}$, and proximity to the pulp and are therefore prone to high recurrence rates. The treatment and management considerations for root caries vary depending upon the extent and location of the lesion, as well as the type of materials being used $^{(5,6)}$.

Several materials and procedures can be used to restore decayed roots. But there is some evidence that glass-ionomer cement may be the material of choice for the restoration of root caries lesions ${ }^{(7)}$. Glass ionomer cements (GICs) are composed primarily of a calcium fluoroaluminosilicate glass powder and an aqueous solution of a homo- or copolymer acrylic acid.

The use of GICs is widespread in dental clinical applications, as luting materials, liners and bases, orthodontic bracket adhesives, core buildups, pit and fissures sealants, and restorative materials ${ }^{(8)}$. GIC has unique properties including its coefficient of thermal expansion close to the tooth structure, biocompatibility, antimicrobial potential, adhesive strength, anticariogenic capability ${ }^{(9)}$, and Fluoride release is considered one of the important advantages of glass-ionomer cements. Fluoride can inhibit demineralization in early carious lesions and promote remineralization of hard dental tissues.
Conversely, GICs have been reported to present clinical limitations such as low wear resistance, low fracture toughness, low mechanical properties, prolonged setting rate, and high early moisture sensitivity ${ }^{(10)}$. These limitations might contribute to restoration failure with bacterial proliferation and consequent recurrent caries and/or teeth or restoration fractures. Efforts have been made to improve GICs' physical and mechanical properties without affecting their biological properties, by the addition of a variety of filler materials including glass fibers ${ }^{(11)}$, hydroxyapetite (HA) ${ }^{(12)}$, bioactive glass particles as pre reacted glass ionomer particles, and casein phosphopeptide-amorphous calcium phosphate ${ }^{(13)}$.

However, literature is sparse in evaluation the combined effect of nano hydroxyapatite and titanium dioxide nanoparticles into conventional glass ionomer, withe or without topical application of nano hydroxyapatite solution, and due to lack definitive action of titanium dioxide on mineralization, and the action of nano hydroxyapatite when added to glass ionomer.

Thus the purpose of present study was to evaluate the remineralizing potential of conventional glass ionomer incorporated with nano hydroxyapatite, titanium dioxide nanoparticles, and nanofilled glass ionomer alone or with a NHA coat.

\section{MATERIALS AND METHODS}

\section{Teeth selection}

A total of 60 freshly extracted sound human Premolars extracted due to orthodontic treatment from patients with average age 18 to 25 years old were included in this study. The teeth were examined to be free from decay or cracks. They were cleaned by soft brush to remove any debris. The teeth were stored at $4^{\circ} \mathrm{C}$ in thymol solution until used. Each sample was embedded in round hollow plastic mould containing chemically cured acrylic resin exposing buccal or lingual surface. Then the 
mold was removed and the resin/ tooth surface was polished using silicon carbide paper until smooth surface have obtained.

\section{Cavity preparation}

A total of 60 standardized rounded class $\mathrm{V}$ cavities were prepared in the middle of cervical one third of the labial and the lingual surfaces of root. A round carbide bur size \# $023^{*}$ with high speed hand piece was used under water coolant. The depth of the cavity was adjusted to $2 \mathrm{~mm}$ by inserting the entire head of the bur ${ }^{(14)}$.

\section{Sample grouping}

The sixty teeth were divided into three main groups according to the experimental restored material (20 specimens each). Group (A): received nano filled glass Ionomer, group (B): received 10\% nano hydroxyapatite incorporated into conventional glass ionomer, and group $(\mathbf{C})$ : received $10 \%$ titanium dioxide nanoparticles incorporated in conventional glass ionomer. Each group was further subdivided into two subgroups of (10 each), according to the topical application of nano hydroxyapatite solution, either the surface was treated with $10 \%$ nano hydroxyapatite solution (I), or the surface was not treated (II).

\section{Preparation of nano particles}

Nano Hydroxyapatite powder: Hydroxyapatite nanoparticles have been prepared in nanotech Egypt by wet chemical method as reported by several authors (15-18). Hydroxyapatite nanoparticles are formed through the wet chemical reaction of calcium nitrate, with ammonium hydroxide ((NH4)2HPO4) the grain size was controlled by changing the time and the temperature of HA precipitation, with $\mathrm{pH}$ values between 10 and 12 and the reaction was performed at room temperature ${ }^{(16,17)}$.

Titanium Dioxide Nanoparticles: Titanium Dioxide nanoparticles have been prepared by wet chemicalmethod, they were successfully synthesized via sol-gel method using Nano crystalline Titanium powders and were synthesized at room temperature (22 C) by a sol-gel method and using $\mathrm{TiCl} 4$ as a precursor with ethanol solution ${ }^{(19-20)}$. After mixing for a specific duration, the gel solution was formed followed by aging. Then the sol-gel dried and cleaned at a room temperature ${ }^{(21,22)}$.

Nano Hydroxyapatite Solution: Supplied as 10\% Nano Hydroxyapatite prepared in NanoTech Company, by dispersed the NHA powder in distilled water.

Demineralization of specimens: Each sample was exposed to $37 \%$ phosphoric acid gel for 2 minutes ${ }^{(23)}$.

Restoration of specimens: Group (A): $(n=20)$ received Nano filled Glass Ionomer, group (B): $(n=20)$ received $10 \%$ Nano hydroxyapatite incorporated into Conventional Glass Ionomer, and group (C): $(n=20)$ received 10\% Titanium dioxide Nanoparticles incorporated in Conventional Glass Ionomer. Each group was further subdivided into two subgroups of (10 each), according to the topical application of Nano Hydroxyapatite solution $(n=10)$; either the surface was treated with $10 \%$ Nano hydroxyapatite solution (I), or the surface was not treated (II).

\section{Restoration of specimens:}

\section{With Nano glass ionomer}

Nano glass ionomer material (3M ESPE Ketac Nano) was applied as follows: the primer was applied before restoration for 15 seconds, it was dried using air syringe for 10 seconds, light cur the primed surface for 10 seconds. The capsule of Nano glass ionomer was triturated by shake it to loosen the powder, then inserted in to the activator click once to activate it, it was removed from the activator then inserted into mixer for 10 seconds, after that it was inserted into applier to dispensed the restoration immediately into the cavity, condensed the material by the tip of capsule or plastic instrument, then exposed the entire area to dental light curing unit for 15 seconds. 
With glass ionomer incorporated with Nano hydroxyapatite

Conventional glass ionomer (3M ESPE Ketac $^{\mathrm{TM}}$ Molar Easymix) incorporated with NHA was prepared by mixed with glass ionomer liquid in proportion of one full spoon of powder to one drop of liquid were mixed on pad, and applied in the cavity till over filled. The excess of cement was removed by sharp instrument.

\section{With glass ionomer incorporated with titanium dioxide nanoparticles}

Conventional glass ionomer with $\mathrm{TiO}_{2} \mathrm{NPs}$ was prepared as CGI with NHA.

\section{Application of Nano hydroxyapatite coat}

The Specimens in subgroups (AI, BI, CI) were exposed to one layer of NHA coat around the restoration by small brush and allowed to dry for 60 seconds.

\section{Remineralization evaluation:}

Specimens were placed in distill water for $24 \mathrm{hrs}$ till specimens were evaluated for minerals change. Results were compared to base line, after demineralization and after remineralization ${ }^{(24)}$.

\section{Energy Dispersive Analytic X-ray (EDAX) analysis}

All samples were analyzed to determine the calcium and phosphorous mineral contents and the changes in the levels of these elements in dentine at base line, before and further treatments. Three points $100 \mu \mathrm{m}$ from cavity margin were selected for analysis, an average of the three points was calculated $^{(25)}$.

The samples were placed under vacuum and excited to higher energy state with an electron beam. As the electrons of each element falls back down to it is original energy state it emits X-ray energy at different specified wavelength. Each element identified by knows wavelength on the $\mathrm{X}$-axis represented by a peak and the intensity of that peak on the Y-axis determine the amount of elements. These minerals were expressed as a weight percentage.

The EDAX was performed using Jole model JSM 6510 LV installed on scanning electron microscope (SEM). The measurements were taken at baseline, after demineralization and remineralization in a point at $1000 \mathrm{X}$ magnification directly on ESEM microscope monitor within the different beams. The specimens were analyzed in the Environmental Scanning Electron operated with backscattered electron mode at 1000X magnification. The mean of the all regions was calculated.

\section{Statistical analysis}

The data was obtained, recorded, tabulated and statistically analyzed by computer using statistical program SPSS ver.17.0* (Statistical Package for Scientific Studies). Numerical data were presented as mean and standard deviation values. Mean and standard deviation values were estimated of quantitative data. Data analysis was performed using one way ANOVA, pair-wise Tukey's post-hoc and Student t-tests.

\section{RESULTS}

\section{Effect of tested materials on remineralization in} each group assessed by EDAX

Effect on Phosphorus content: Table (1) showed the mean, standard deviation (SD) and probability $(\mathrm{P})$ value of phosphorus $(\mathrm{P})$ weight\% values respectively at baseline, demineralization and remineralization of all experimental groups. There was statistically significant decrease in phosphorus content after demineralization, followed by statistically significant increase in phosphorus after remineralization in coated and no coated of all groups. 
Table (1): Descriptive statistics of $P$ Weight\% values in all groups.

\begin{tabular}{|c|c|c|c|c|c|c|c|c|}
\hline \multicolumn{2}{|c|}{ Experimental group } & \multicolumn{2}{|c|}{ Baseline } & \multicolumn{2}{|c|}{ Demineralization } & \multicolumn{2}{|c|}{ Remineralization } & \multirow[t]{2}{*}{$P$ value } \\
\hline \multirow{3}{*}{ NGI } & & Mean & SD & Mean & SD & Mean & SD & \\
\hline & No coat & 7.90 & 1.00 & 2.13 & 0.46 & 8.07 & 0.07 & $0.0000 *$ \\
\hline & Coat & 8.91 & 3.12 & 3.16 & 1.35 & 9.04 & 0.67 & $0.0007 *$ \\
\hline \multirow{2}{*}{ NHA } & No Coat & 7.26 & 1.48 & 3.20 & 0.76 & 13.45 & 1.01 & $0.0000 *$ \\
\hline & Coat & 9.35 & 2.20 & 3.94 & 0.84 & 17.09 & 1.46 & $0.0000 *$ \\
\hline \multirow{2}{*}{ TiO2 NP } & No Coat & 8.12 & 0.89 & 4.01 & 0.61 & 7.81 & 1.46 & $0.0000^{*}$ \\
\hline & Coat & 7.76 & 1.03 & 2.96 & 0.58 & 10.69 & 3.70 & $0.0005 *$ \\
\hline
\end{tabular}

Effect on Calcium content: Table (2) and figures $(1,2,3)$ showed the mean, standard deviation $(\mathrm{SD})$ and probability $(\mathrm{P})$ value of calcium $(\mathrm{Ca})$ weight $\%$ values respectively at baseline, demineralization and remineralization of all experimental groups. group.

Table (2): Descriptive statistics of Ca Weight\% values in all groups.

\begin{tabular}{|c|c|c|c|c|c|c|c|c|}
\hline \multicolumn{2}{|c|}{ Experimental group } & \multicolumn{2}{|c|}{ Baseline } & \multicolumn{2}{c|}{ Demineralization } & \multicolumn{2}{c|}{ Remineralization } & P value \\
\hline \multirow{3}{*}{ NGI } & & Mean & SD & Mean & SD & Mean & SD & \\
\cline { 2 - 10 } & No coat & 11.8 & 0.6 & 3.19 & 0.76 & 9.37 & 0.33 & $0.0000 *$ \\
\cline { 2 - 10 } & Coat & 11.70 & 4.07 & 4.85 & 1.79 & 10.44 & 0.73 & $0.0031 *$ \\
\hline \multirow{3}{*}{ NHA } & No Coat & 12.15 & 1.33 & 5.59 & 0.71 & 19.39 & 1.02 & $0.0000 *$ \\
\cline { 2 - 10 } & Coat & 14.41 & 2.43 & 5.92 & 0.81 & 21.20 & 1.60 & $0.0000 *$ \\
\hline \multirow{3}{*}{ TiO2 NP } & No Coat & 11.82 & 0.79 & 5.55 & 1.33 & 12.56 & 2.37 & $0.0000 *$ \\
\cline { 2 - 10 } & Coat & 11.62 & 0.38 & 4.71 & 0.30 & 16.75 & 6.76 & $0.0014 *$ \\
\hline
\end{tabular}

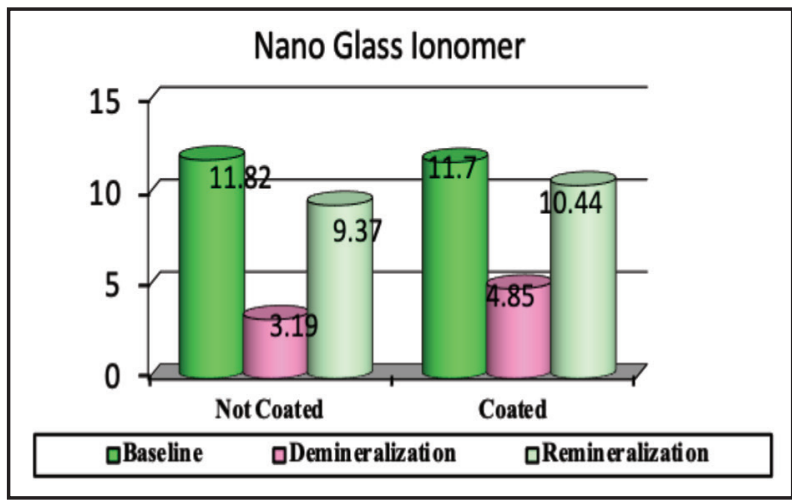

Figure (1) A bar chart showing mean values of calcium mineral weight in both coated and uncoated subgroups at different stages in group (A) NGI.
There was statistically significant decrease in calcium content after demineralization, followed by statistically significant increase in calcium content after remineralization in coated and no coated of all 


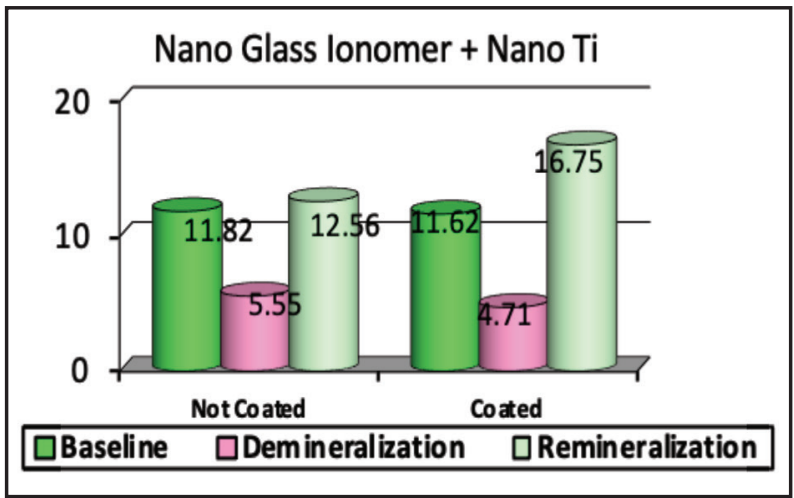

Figure (3) A bar chart showing mean values of calcium mineral weight in both coated and uncoated subgroups at different stages in group (C) GI with TiO2 NPs.

\section{Comparison between experimental groups:}

Effect of restorative material on mineral content as assessed by $\mathrm{EDAX}$

Comparison of percent Change of calcium in all groups: Table (3) showed no statistically significant difference in calcium\% change between the three materials in both coated and no coated groups.
Table (3): Comparing mean percentage change\% of Calcium ( $\mathrm{Ca}$ ) between restorative materials in both coated and uncoated groups.

\begin{tabular}{|c|c|c|c|c|}
\hline \multirow{2}{*}{$\begin{array}{c}\text { Experimental } \\
\text { material }\end{array}$} & \multicolumn{2}{|c|}{ No coat } & \multicolumn{2}{c|}{ Coat } \\
\cline { 2 - 5 } & Mean & SD & Mean & SD \\
\hline NGI & 204.98 & 60.71 & 137.21 & 77.54 \\
\hline NHA & 252.11 & 54.57 & 263.70 & 56.36 \\
\hline TiO $_{2}$ NP $_{\mathrm{S}}$ & 140.16 & 91.69 & 256.04 & 141.00 \\
\hline P values $^{\mid r y y y}$ & $0.080 \mathrm{NS}$ & \multicolumn{2}{|c|}{$0.116 \mathrm{NS}$} \\
\hline
\end{tabular}

Effect of coat on percentage change of mineral gain (phosphorus and calcium):

Table (4) showed no statistically significant difference in Phosphorus and calcium percentage change in coated and non-coated subgroups, except in $\mathrm{TiO}_{2}$ NPS showed significant increase in percentage change of phosphorus.

Table (4): Comparing percent change \% of calcium and phosphorus mineral gain after remineralization in both coated and no coated of all groups.

\begin{tabular}{|c|c|c|c|c|c|c|}
\hline \multirow{2}{*}{$\begin{array}{c}\text { Experimental } \\
\text { group }\end{array}$} & \multirow{2}{*}{ Minerals } & \multicolumn{2}{|c|}{ No coat } & \multicolumn{2}{c|}{ Coat } & Pvalue \\
\cline { 2 - 7 } & & Mean & SD & Mean & SD \\
\hline \multirow{2}{*}{ NGI } & $\mathbf{P}$ & 288.98 & 63.80 & 227.06 & 120.38 & 0.170 \\
\cline { 2 - 7 } & $\mathbf{C a}$ & 204.98 & 60.71 & 137.21 & 77.54 & 0.081 \\
\hline \multirow{2}{*}{ NHA } & $\mathbf{P}$ & 337.24 & 96.17 & 348.84 & 95.32 & 0.426 \\
\cline { 2 - 7 } & $\mathrm{Ca}$ & 348.84 & 95.32 & 263.70 & 56.36 & 0.062 \\
\hline \multirow{2}{*}{$\mathrm{TiO}_{2} \mathrm{NP}_{\mathrm{S}}$} & $\mathrm{P}$ & 95.02 & 27.79 & 254.39 & 63.55 & $0.0004 *$ \\
\cline { 2 - 7 } & $\mathrm{Ca}$ & 140.16 & 91.69 & 156.04 & 141.00 & 0.081 \\
\hline
\end{tabular}




\section{DISCUSSION}

In this study, when evaluating remineralizing effect of the tested restorative materials, results showed that all materials caused significant remineralization of dentine. The potential of remineralization of carious lesions in dentin in vitro by glass-ionomer cements (GIC) has been long established, and related to the release of fluoride ions from the restorative material. Diffusion of additional ions from GIC, like calcium, and phosphate has an additional effect on remineralized dentin in vivo in permanent teeth ${ }^{(26)}$. Those results are in agreement with others studies ${ }^{(27,28)}$, which showed significant remineralization effect of Nano glass ionomer on dentin.

Results showed increase in mineralization when was added NHA to glass ionomer, this was in agreement with other study ${ }^{(29)}$, which reported that NHA had the potential to remineralize tooth lesions. The remineralizing effect of NHA on demineralized enamel and dentin has also been confirmed in several other studies ${ }^{(21,22,23,24)}$. The HA nanoparticles penetrate into the porosities and act like a scaffold. They uptake calcium and phosphate ions from the remineralizing solution and lodge them into the superficial enamel. By doing so, they fill the gaps in between the enamel calcium crystals, yielding a uniform crystalline enamel structure.

Hydroxyapatites have been used to improve the properties of glass ionomers. The HA is the main mineral compound in the structure of teeth and bone. Its small particle size, similar to other minerals in the tooth structure, confers increased surface area and high solubility. The NHA, due to high solubility, can efficiently fill the micro-pores present in enamel and dentin defects by releasing inorganic ions like calcium and phosphate, increase resistance to demineralization and improve the bond strength of restorative materials to tooth. The results of present study is supported by numerous studies ${ }^{(12,30)}$ have demonstrated that addition of NHA to GIC increased resistance to demineralization. Due to small particle size, NHA can deposit on the demineralized enamel. Moreover, high solubility of NHA results in efficient release of calcium and phosphate ions that fill the micro-pores. Penetration of inorganic ions and HA particles into the demineralized tooth surface prevents the wash-off of calcium ions released from the enamel surface; thus, resistance to demineralization increases.

The titanium dioxide nanoparticles showed effectiveness in remineralization. Those results were supported by another study (31) found the dental adhesives containing $\mathrm{TiO}_{2} \mathrm{Ns}_{\mathrm{s}}$ were shown to be bioactive in terms of spontaneous hydroxyapatite formation than pure adhesive. This was attributed to the surface chemistry and charge of titanium dioxide nanoparticles, which can modify the surface and producing a negative surface charge, inducing growth of new hydroxyapatite by attraction of $\mathrm{Ca}$ ions to the surface to produce a positively charged surface, which in turn leads to attraction of $\mathrm{P}$ ions to it, thus forming hydroxyapatite.

The $\mathrm{TiO}_{2}$ NPs when comparing mineral content with NHA and GI, Titanium dioxide Nano particles incorporated into conventional glass ionomer showed significantly lower phosphorus\% change than both Nano glass ionomer group and Nano hydroxyapatite incorporated with conventional glass ionomer. Those results are in line with previous study ${ }^{(32)}$, which found the $\mathrm{TiO}_{2} \mathrm{NPs}$ was attributed to that; either titanium dioxide nanoparticles cannot provide a uniform surface for the hydroxyapatite growth, or the surrounding the nanoparticles affects the environment for hydroxyapatite growth. This difference could be related to the technique of synthesis of titanium dioxide, which may affect the bioactivity.

In comparing use of coat of nano hydroxyapatite particles, it results that generally, Phosphorus and calcium percentage change in coated and noncoated subgroups showed non-statistically significant difference, except in $\mathrm{TiO} 2$ group were the coat caused significant increase in percentage change of phosphorus. 
Results concerned effect of coat with $\mathrm{TiO}_{2} \mathrm{NPs}$ there was an increase the mineral content especially $\mathrm{P}$. This may be due to the fact that $\mathrm{TiO}_{2}$ NPs was not on par with the other materials in remineralization, and the added coat may have provided a better scaffold for HA crystals formation. And also, may be due to that the restorative material provided sufficient remineralization saturating the surface with minerals. This is agreement with pervious study ${ }^{33)}$, which evaluated a variety of dental restorative materials is able to promote tooth remineralization and/or inhibit tooth demineralization.

\section{CONCLUSION}

It was concluded the modification of conventional glass ionomer restorations using nano particles is beneficial to dentin remineralization, and nanohydroxyapatite topical coat has limited beneficial effect when used in conjunctional with nanohydroxyapatite and nano glass ionomer restoration. Titanium dioxide nanoparticles although produces remineralization, is of lesser value than NHA NPs.

\section{REFERENCES}

1. Banting DW. The Diagnosis of Root Caries. J Dent Edu. 2001; 65:991-6.

2. Banting DW, Ellen R, Fillery E. A longitudinal study of root caries: baseline and incidence data. J Dent Res. 1985; 64:1141-4.

3. Lynch E, Beighton D. A comparison of primary root caries lesions classified according to colour. Caries Res. 1994; 28:233-9

4. Shaeken M, Keltjens H, Hoeven J. Effects of fluoride and chlorhexidine on the microflora of dental root surfacs and progression of root-surface caries. J Dent Res. 1991; 70:150-3.

5. Fure S. Five-year incidence of coronal and root caries in 60-70- and 80-year-old Swedish individuals. Caries Res. 1997; 31:249-58.

6. Banting DW, Papas A, Clark D, Proskin H, Schultz M, Perry R. The effectiveness of $10 \%$ chlorhexidine varnish treatment on dental caries incidence in adults with dry mouth. Gerodontology. 2001; 17:2-11.
7. Vehkalahti M, Rajala M, Tuominen R, Paunio I. Prevalence of root caries in the adult Finnish population. Community Dent Oral Epidemiology. 1983; 11:188-90.

8. Wilsonand B, Kent E. Anew translucent cement for dentistry. The glass ionomer cement. British Dent J. 1972; 132:133-5.

9. Brentegani L, Bombonato $\mathrm{K}$, LamanoCarvalho L, Histological evaluation of the biocompatibility of a glass ionomer cement in rat alveolus. Biomaterials. 1997; 18:137-40.

10. Pereira L, Nunes M, Dibb R, Powers J, Roulet J, Navarro F. Mechanical properties and bond strength of glass ionomer cements. J Ad Dent. 2002; 4:73-80.

11. Hammouda M, Reinforcement of conventional glass ionomer restorative material with short glass fibers. J Mech Behav Biomed Mat. 2009; 2:73-81.

12. Lucas M, Arita KE, Nishino M. Toughness, bonding and fluoride release properties of hydroxyapatite added glass ionomer cement. Biomaterials. 2003; 24:3787-94.

13. Zraikat H, Palamara J, Messer H, Burrow F, Reynolds C, "The incorporation of casein phosphopeptide amorphous calcium phosphate into a glass ionomer cement. Dent Mat. $2011 ; 27: 235-43$.

14. Ameri H, Chasteen JE, Ghavamnasiri M, Maghami A. Effect of load cycling on nanoleakage of butt joint and beveled occlusal enamel margins in class $\mathrm{V}$ composite resin restorations. Rev Clin pesq Odontol. 2010; 6:231-7.

15. Jarcho M, Kay J, Gumaer K, Doremus R, Drobeck H. Tissue, cellular and subcellular events and bon-ceramic hydroxyapatite interface. J Bioeng. 1977; 1:79-92.

16. Yubao L, de Groot K, de Wijn J, Klein C, Meer S. Morphology and composition of nanograde calcium phosphate needle-like crystals formed by simple hydrothermal treatment. J Mat Sci Mat Med. 1994; 5:326-31.

17. Yubao L, Klein, C.P.A.T, de Wijn J, Wolke J, de Groot K. Morphology and phase structure of nanograde boneapatite-like rodshaped crystals. Bioceram confer. 1993; 173-8.

18. Adrian P, Dainelys G, Mónica L, Jesús EG, Nayrim B, Javier A. A comparative study of hydroxyapatite nanoparticles synthesized by different routes. Quim Nova. 2012; 35:1724-7.

19. Dalvandi M, Ghasemi B. Synthesis of titanium dioxide nano-powder via sol-gel method at ambient temperature. J Scien Tech. 2013; 66: 68-72. 
20. Chaudhary V, Srivastava A, Kumar J. On the Solgel Synthesis and Characterization of Titanium Oxide Nanoparticles. Mater Res Soc. 2011; 1352:557-9.

21. Shahruz N, Hossain M. Synthetesis and Size-Control of $\mathrm{TiO} 2$ Photocatalyst Nanoparticles preparation using SolGel Method. W Scien J. 2011; 12:1981-6.

22. Thangavelu K, Annamalai R, Arulnandhi D. Effective Usability Testing - Knowledge of User Centered Design is a Key Requirement. Int J Emerg Tech Adv Eng. 2013; 3:636-9.

23. Rosianu R, Sinescu C, Negrutiu M, and Tudor A. Microscopic assessment of the enamel-etching pattern according to different etching time using orthophosphoric acid gels. Mat Plast. 2016; 53:153-6.

24. U Lee JJ, Nettey-Marbell A, Cook A, Pimanta LA, Leonard R, Ritter A. Using extracted teeth for research: the effect of storage medium and sterilization on dentin bond strength. J Am Dent Assoc. 2007; 138:1599-603.

25. Aykaut-Y, Simsek D, Eronat C, Ciftcioglu M. Comparison of the remineralisation effect of glass ionomer cement versus a resin composite on dentin of primary teeth. Eur J Pead Dent. 2014; 15:119-21.

26. Zilberman U. Ion exchanges between glass-ionomer restorative material and primary teeth components - an in vivo study. Oral bio dent. 2014; 2:1-2.
27. Kuhn E, Chibinski AC, Reis A, Wambier DS. The role of glass ionomer cement on the remineralization of infected dentin: an in vivo study. Ped Dent. 2014; 36:118-24.

28. Aykut-Yetkiner A, Simşek D, Eronat C, Ciftçioğlu M. Comparison of the remineralisation effect of a glass ionomer cement versus a resin composite on dentin of primary teeth. Eur J Ped Dent. 2014; 15:119-21.

29. Huang S, Gao S, Yu H. Effect of nano-hydroxyapatite concentration on remineralization of initial enamel lesion in vitro. Biomed Mater. 2009; 4:341-4.

30. Tschoppe P, Daniela L, Zandim, Peter M, Andrej M. Kielbassa. Enamel and dentine remineralization by nano hydroxyapatite toothpastes. J Dent. 2011; 39:430 -7.

31. Haghgoo R, Mohammad A, Sara T, Hojjati S, Sara R. The effect of various amounts of nanohydroxyapatite on the mechanical properties and remineralization of a fissure sealant. J Dent Sch. 2012; 30:184-91.

32. Asghar E, Mohammad N, and Sayed AF. Effect of nano hydroxyapatite toothpaste on microhardness of artificial carious lesions created on extracted teeth. J Dent Res Dent Clin Dent Prospects. 2017; 11:14-7.

33. Huang S, Gao S, Cheng L, Yu H. Combined effects of nano hydroxyapatite and Galla chinensis on remineralisation of initial enamel lesion in vitro. J Dent. 2010; 38:811-9. 